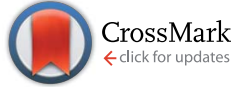

Cite this: RSC Adv., 2015, 5, 41428

\title{
Tailoring of PEEK bioactivity for improved cell interaction: plasma treatment in action
}

\author{
Zdenka Novotna, ${ }^{* a}$ Alena Reznickova, ${ }^{a}$ Silvie Rimpelova, ${ }^{\mathrm{b}}$ Martin Vesely, ${ }^{\mathrm{c}}$ \\ Zdenka Kolska ${ }^{d}$ and Vaclav Svorcik ${ }^{a}$
}

\begin{abstract}
Despite the extensive use of polyetheretherketone (PEEK) in biomedical applications, information about cell adhesion on this biomaterial is limited. This study focuses on PEEK tuned by argon plasma treatment with the aim to enhance its wettability and cytocompatibility. Changes in surface properties of the plasma treated surface were studied in relation to the adhesion, proliferation and metabolic activity of mouse fibroblasts (L929) and human osteoblast (U-2 OS) in vitro. Moreover, the expression profiles of two proteins (talin 1 and vinculin) responsible for cell adhesion, were determined at 2 time points in dependence on the PEEK treatment. Plasma treatment increased the surface wettability of PEEK and led to changes in its surface morphology and chemistry. The XPS method showed a decrease in carbon content and augmentation of oxygen concentration with increasing effect of the plasma. Plasma treatment of PEEK significantly enhanced cell adhesion, proliferation and metabolic activity of both cell lines when compared to pristine PEEK. Moreover, special attention was devoted to filopodia of L929 cell adhered on PEEK studied by means of scanning electron microscopy. The most abundant filopodia were present on PEEK plasma treated for "longer" times.
\end{abstract}

Received 4th March 2015

Accepted 24th April 2015

DOI: $10.1039 / \mathrm{c} 5 \mathrm{ra} 03861 \mathrm{~h}$

www.rsc.org/advances

surface characteristics into account, further modifications of

\section{Introduction}

Polyetheretherketone (PEEK) has been used as an alternative to metallic implants for orthopedics and active medical implant applications, such as, the Eon spinal cord stimulation device. ${ }^{\mathbf{1 , 2}}$ This polymer is a semicrystalline material possessing high thermal stability, chemical resistance, ${ }^{3}$ and good mechanical properties. $^{4,5}$ Furthermore, PEEK exhibits good biocompatibility in vitro and in vivo, causing neither toxic and mutagenic effects nor clinically significant inflammation. ${ }^{6-8}$

The biggest advantage of PEEK is elasticity which is similar to that of a human bone. ${ }^{9}$ This fact allows an even load distribution between the implant and the bone, ${ }^{2}$ therefore the phenomenon of stress shielding does not occur after material implantation. ${ }^{\mathbf{1}, 9}$ Furthermore, PEEK has a good combination of other properties: stiffness, ${ }^{\mathbf{1 0}}$ tensile strength, distortion, abrasion, and fatigue resistance. ${ }^{\mathbf{1 1 , 1 2}}$ However, PEEK is chemically inert and due to its hydrophobic surface, it allows neither protein absorption nor promotes cell adhesion. ${ }^{13}$ Taking PEEK

${ }^{a}$ Department of Solid State Engineering, University of Chemistry and Technology, Prague, Czech Republic. E-mail: zdenka1.novotna@vscht.cz; Fax: +420 220444 330; Tel: +420220445159

${ }^{b}$ Department of Biochemistry and Microbiology, University of Chemistry and Technology, Prague, Czech Republic

'Department of Organic Technology, University of Chemistry and Technology, Prague, Czech Republic

${ }^{d}$ Faculty of Science, J. E. Purkyne University in Usti nad Labem, Usti nad Labem, Czech Republic this primarily inert polymer are crucial in order to enhance cell adhesion and biocompatibility.

Surface properties which influence cell adhesion include surface hydrophilicity, morphology (such as crystalline and amorphous domains), topography (roughness), surface energy, electrical charge, and chemical composition. ${ }^{\mathbf{1 4}, 15}$ PEEK exhibits a hydrophobic bio-inert surface characteristics which are not favorable for protein adsorption and cell adhesion. ${ }^{16,17}$

Therefore the surface of PEEK needs to be surface modified in order to enhance cells attachment. For example, plasma treatment is used for tailoring surface physical and chemical properties without affecting the bulk properties (especially mechanical ones) of the base material, which is advantageous in the design, development, and manufacturing of biocompatible polymers. The plasma treatment of polymers leads to the creation of new chemical groups, ${ }^{18}$ cross-linking and branching of the macromolecules and formation of low-molecular weight oxidized structures, ${ }^{19}$ the rates of these processes being a function of the plasma reactivity. Due to ablation the surface topography of the polymer is affected..$^{20}$ Plasma etching treatments are applied to biomedical material surfaces for cleaning (major usage), sterilization, wettability improvement, providing reactive sites, and crosslinking surface molecules. ${ }^{21}$

Hence, the objective of this study was to investigate adhesion and spreading of mouse fibroblasts (L929) and human osteoblast (U-2 OS) in vitro on PEEK surfaces treated to argon (Ar) plasma. Surface properties of PEEK were studied by different 
experimental techniques: goniometry, X-ray photoelectron spectroscopy (XPS) and electrokinetic analysis were used to determine the surface wettability, polarity and chemistry of the treated polymer, respectively. Further, atomic force microscopy (AFM) was employed to study the surface morphology and roughness of the pristine and plasma treated samples. The biological response of the two model cell lines incubated with untreated and plasma treated PEEK matrices was quantified in terms of the cell density, viability, spreading, and morphology.

\section{Experimental}

\subsection{Materials and plasma treatment}

The PEEK foil (thickness $75 \mu \mathrm{m}$, supplied by Goodfellow Cambridge Ltd., UK) was used for all experiments. The PEEK samples were treated in direct current (DC, glow, diode) $\mathrm{Ar}^{+}$ plasma on Balzers SCD 050 device under the following conditions: gas purity $99.997 \%$, flow rate $0.3 \mathrm{l} \mathrm{s}^{-1}$, pressure $10 \mathrm{~Pa}$, electrode distance $50 \mathrm{~mm}$ and area of $48 \mathrm{~cm}^{2}$, chamber volume approx. $1000 \mathrm{~cm}^{3}$, and plasma volume $240 \mathrm{~cm}^{3}$. Treatment times were 120, 240 and $480 \mathrm{~s}$, discharge power $8.3 \mathrm{~W}$ (room temperature, RT). The samples were cleaned by nitrogen flow. More detailed description of the plasma treatment of polymers can be found in (ref. 22).

\subsection{Measurement techniques}

Water contact angles (WCA) of distilled water, characterizing structural and compositional changes caused by the plasma treatment, were measured at RT on two samples at seven positions each using a drop shape analyzer (DSA 100, KRÜSS GmbH, DE). Drops of $2.0 \pm 0.2 \mu \mathrm{l}$ of water were deposited on the tested samples using an automatic pipette. Images of the drops were taken after a $2 \mathrm{~s}$ delay. Contact angles were then evaluated using the Surface Energy Evaluation System (Advex Instruments, CR).

Chemical composition of the prepared structures was determined from X-ray photoelectron spectra (XPS) measured by Omicron Nanotechnology ESCAProbeP spectrometer with a relative error of $10 \%$. X-Ray source was monochromated at $1486.7 \mathrm{eV}$ and area of $2 \times 3 \mathrm{~mm}^{2}$ was exposed and analyzed. Spectra were measured stepwise with a binding energy step of $0.05 \mathrm{eV}$, the takeoff angle was $0^{\circ}$ according to surface normal. The spectra evaluation was carried out using CasaXPS program. The samples used for measurement were "aged" for 14 days. Before the measurement the samples were stored under standard laboratory conditions.

The surface morphology of the samples was examined by atomic force microscopy (AFM) using VEECO CP II system, surface roughness $\left(R_{\mathrm{a}}\right)$ was measured in "tapping mode" with silicon P-doped probes RTESPA-CP with the spring constant 20-80 $\mathrm{N} \mathrm{m}^{-1}$. By repeated measurements of the same region $\left(2 \times 2 \mu \mathrm{m}^{2}\right)$ we proved that the surface morphology did not change after three consecutive scans. The samples used for measurement were "aged" for 14 days.

Electrokinetic analysis (electrokinetic potential, zeta potential) of all samples was determined by SurPASS Instrument (Anton Paar). Samples were studied inside an adjustable gap cell in contact with the electrolyte $\left(0.001 \mathrm{~mol} \mathrm{l}^{-3} \mathrm{KCl}\right)$. For each measurement a pair of polymer films with same top layer was fixed on two sample holders (with a cross section of $20 \times 10$ $\mathrm{mm}^{2}$ and gap between $\left.100 \mu \mathrm{m}\right)$. All samples were measured three times at constant $\mathrm{pH}$ value with the relative error of $5 \%$. For the determination of the zeta potential the streaming current method was used and the Helmholtz-Smoluchowski equation was applied to calculate zeta potential. ${ }^{23}$ The samples used for measurement of zeta potential were "aged" for 14 days.

\subsection{Cell culture}

The adhesion and proliferation of human osteoblast (U-2 OS; ATCC, USA) and mouse fibroblasts (L929; Sigma, USA) on pristine and treated PEEK samples were studied in vitro.

First, the PEEK samples were sterilized in $70 \%$ ethanol in Petri dish, inserted in 12-well plates (VWR, USA, Ø $2.14 \mathrm{~cm}$ ), washed by PBS and mounted to the well bottom with hollow plastic cylinders from poly(methyl methacrylate).

U-2 OS and L929 cells were seeded on the samples in the density of 30000 cells per $\mathrm{cm}^{-2}$ in $1 \mathrm{ml}$ of high glucose Dulbecco's Modified Eagle Minimum Essential Medium (DMEM; Sigma, USA) containing $10 \%$ fetal bovine serum (FBS, Invitrogen, USA) and $2 \mathrm{mM}$ L-glutamine (Sigma, USA). The cells were cultivated on the samples for 6,24 and $72 \mathrm{~h}$ at $37{ }^{\circ} \mathrm{C}$, humidity $95 \%$ and $5 \% \mathrm{CO}_{2}$.

The cells were fixed and stained similarly as described in. ${ }^{24,25}$ U-2 OS and L929 cells were washed with PBS and fixed with 4\% formaldehyde (Thermo Scientific, USA) in PBS (37 $\left.{ }^{\circ} \mathrm{C}, 20 \mathrm{~min}\right)$. After PBS washing, the cell cytoskeleton was labeled with phalloidin-Atto 565 (Sigma, USA) in PBS for $20 \mathrm{~min}$. Then, cell nuclei were stained with DAPI (4',6-diaminido-2-phenylindole dihydrochloride, Sigma, USA) for $10 \mathrm{~min}$, the cells were rinsed with PBS, covered with mounting medium (Vector Laboratories, USA), and mounted between two glass slides.

Fluorescence microscopy was performed using an inverse fluorescence microscope Olympus IX-81 (Xcellence system). The $10 \times$ lens was used to cover the largest field of view for cell counting, $20 \times$ and $40 \times$ lenses were used to study cell morphology in greater detail. High stability $150 \mathrm{~W}$ xenon arc burner was used as a light source. Images were recorded by EMCCD camera C9100-02 (Hamamatsu, Germany). The rate of cell adhesion and proliferation was determined as a function of cell culture time by analyses of the number of cell nuclei (from 20 images). Cell adhesion was determined $6 \mathrm{~h}$ after inoculation, proliferation after 24 and $72 \mathrm{~h}$ of cell growth. Image 1.47 software (National Institute of Health, USA) was used for semiautomatic evaluation of the cell number. All samples ("aged" for 14 days) were tested in triplicates.

Metabolic activity of the cells growing on PEEK substrates was determined by the WST-1 assay (Roche, Germany), which is based on tetrazolium salt reduction by mitochondrial oxidoreductases in viable cells into soluble formazan. U-2 OS and L929 cells were seeded on PEEK samples in 12-well plates (30 000 cells per well) in $1 \mathrm{ml}$ of cultivation medium (triplicates). Cell metabolic activity was assessed after 24 and $72 \mathrm{~h}$ of growth, then the culture medium was removed and replaced 
with $0.475 \mathrm{ml}$ of fresh media without phenol red supplemented with $25 \mu \mathrm{l}$ of WST-1. The cells were incubated for another $2 \mathrm{~h}$, then the arisen formazan was measured at $450 \mathrm{~nm}$ (reference at $630 \mathrm{~nm}$ ). Metabolic activity of all the samples ("aged" for 14 days) was measured in triplicates.

\subsection{SEM analysis}

Detailed morphology of cells growing on pristine, plasma treated PEEK and control (microscopic glass slides) was characterized by Scanning Electron Microscopy (SEM) TESCAN LYRA3 GMU (Tescan, CZ) in secondary-electron mode. The cells intended for analysis by SEM were washed with PBS $(\mathrm{pH}=7.4)$ and fixed by Karnovsky solution ${ }^{26,27}$ and dehydrated by ethanol. The dehydrated samples were coated by a thin layer of gold $(10 \mathrm{~nm})$. The samples used for cell morphology assessment were "aged" for 14 days.

\subsection{Western blot analysis}

The level of talin 1 and vinculin expression in L929 and U-2 OS cells was assessed using Western blot analysis. Cells were inoculated on the examined samples (PEEK, plasma treated PEEK for 120, 240, and $480 \mathrm{~s}$, TCPS) and incubated for $6 \mathrm{~h}\left(10^{5}\right.$ cells per well of 12 -well $)$ and for $24 \mathrm{~h}\left(5 \times 10^{4}\right.$ cells per well). The cell number for each cultivation time was chosen to achieve the same cell mass (cell generation time ca. 20-24 h). After the elapsed period, the cells were lysed by $2 \times$ concentrated Laemmli buffer (volume $150 \mu \mathrm{l}$; composition: $150 \mathrm{mM}$ Tris, $\mathrm{pH}$ $=6.8,8 \%$ SDS, $24 \%$ glycerol, $0.02 \%$ Coomassie blue G-250, 200 $\mathrm{mM}$ D,L-dithiothreitol), sonicated ( $1 \mathrm{~W}, 5 \mathrm{~s})$ on ice, and boiled for $5 \mathrm{~min}$. Then, the proteins in cell lysates were separated by $10 \%$ Tris-glycine SDS-PAGE and electroblotted onto a nitrocellulose membrane (100 V, $60 \mathrm{~min})$. The membrane was incubated with $5 \%$ fat-free milk (w/v) and $0.1 \%$ Tween-20 (v/v) in PBS for $1 \mathrm{~h}$ in order to block nonspecific interactions of a primary antibody. Talin 1, vinculin and GAPDH were detected using monoclonal antibodies: anti-talin 1 (Sigma, USA; 1 : 1000), antivinculin (Santa-Cruz; $1: 1000$ ), and polyclonal anti-GAPDH (Santa-Cruz; $1: 10$ 000), respectively. Secondary antibodies, anti-mouse and anti-rabbit IgG, conjugated with horseradish peroxidase (Promega) were applied in 1:4000 dilution. The proteins of desire were visualized using Super Signal West Femto chemiluminescent substrate (Pierce). The chemiluminescence was recorded by CCD camera Fujifilm Las 1000 . Samples were quantified by Image J 1.47. The level of talin 1 and vinculin expression in L929 and U-2 OS cells of the all samples ("aged" for 14 days) were measured in triplicates.

\subsection{Statistics}

The presented results were calculated as an arithmetic mean with a standard deviation. To achieve required statistical significance and decrease the standard deviation, measurements were repeated on a number of samples and different positions. The acquired data was first tested to have normal distribution (using the Shapiro-Wilk $W$ test - almost all the experimental data was found to obey the normal distribution).
When the normal distribution was confirmed, the mean values and standard deviations were calculated.

\section{Results and discussion}

The characteristic response of biomaterials in a biological environment is tied to their surface properties. In this work, surface properties of pristine and plasma treated PEEK have been investigated by several analytical methods.

It is well known that cytocompatibility of substrates is strongly influenced by wettability (water contact angle) of their surface. The values of water contact angle (WCA) measured in dependence on the treatment time of samples are shown in Table 1. Goniometry measurements of PEEK samples were performed immediately (15 min) and 14 days ("aged" of samples thanks reorientation of created polymer segments by plasma treatment ${ }^{28}$ ) after the plasma treatment. All samples measured immediately after plasma treatment exhibited significantly decreased values of contact angles. WCA of pristine PEEK was $79.5^{\circ}$. Plasma treated surface of PEEK showed WCA in the range of $18.9-23.2^{\circ}$. The wettability of PEEK slightly raised with increasing plasma treatment duration. The aged polymer surface (after 14 days) showed also hydrophilic properties compared to pristine PEEK. The most hydrophilic surface was present on PEEK/240 s (48.3), and became more hydrophobic with increasing time of treatment (PEEK/480 s, 64.7 ${ }^{\circ}$ ). The decrease of contact angle is connected with changes in surface chemistry thanks surface ablation of polymer by plasma treatment. ${ }^{30}$

The results of XPS measurement of $\mathrm{C}$ and $\mathrm{O}$ concentrations on pristine and plasma treated polymer are shown in Table 1. From XPS measurement (analysis depth of 6-8 atomic layers), one can see that the carbon concentration decreased with increasing treatment duration. This was probably caused by ablation during which the oxygen groups produced by the plasma treatment reorientate themselves into the bulk. The reorientation of polar groups in the polymer surface layer major role in this process plays. ${ }^{29}$ The carbon content decreased in the plasma treated samples from $86.9 \%$ (pristine PEEK) to 50.9\% $(\mathrm{PEEK} / 480 \mathrm{~s})$. On the other hand, oxygen concentration increased, which confirms the presence of polar groups in

Table 1 Dependence of PEEK's water contact angles (WCA measured by goniometry, 15 min and 14 days after treatment) and concentration of carbon and oxygen (by XPS) on Ar plasma (by $8.3 \mathrm{~W}$, treatment time 120, 240, and $480 \mathrm{~s})$ [PEEK, PEEK/120 s, PEEK/240 s and PEEK/480 s]. The error of contact angle measurement was below $2.5^{\circ}$ and error of XPS was $\pm 5 \%$

\begin{tabular}{|c|c|c|c|c|}
\hline \multirow[b]{2}{*}{ Sample } & \multicolumn{2}{|l|}{ WCA $\left(^{\circ}\right)$} & \multicolumn{2}{|c|}{$\begin{array}{l}\text { Element } \\
\text { concentration } \\
(\text { at } \%)\end{array}$} \\
\hline & $15 \mathrm{~min}$ & 14 days & $\mathrm{C}(1 \mathrm{~s})$ & $\mathrm{O}(1 \mathrm{~s})$ \\
\hline PEEK & $79.5 \pm 2.4$ & $79.5 \pm 2.4$ & 88.8 & 11.2 \\
\hline PEEK/120 S & $23.2 \pm 1.8$ & $55.1 \pm 2.2$ & 67.3 & 32.7 \\
\hline PEEK/240 s & $21.8 \pm 1.3$ & $48.3 \pm 1.9$ & 60.1 & 39.9 \\
\hline PEEK/480 s & $18.9 \pm 1.7$ & $64.7 \pm 2.1$ & 51.4 & 48.6 \\
\hline
\end{tabular}



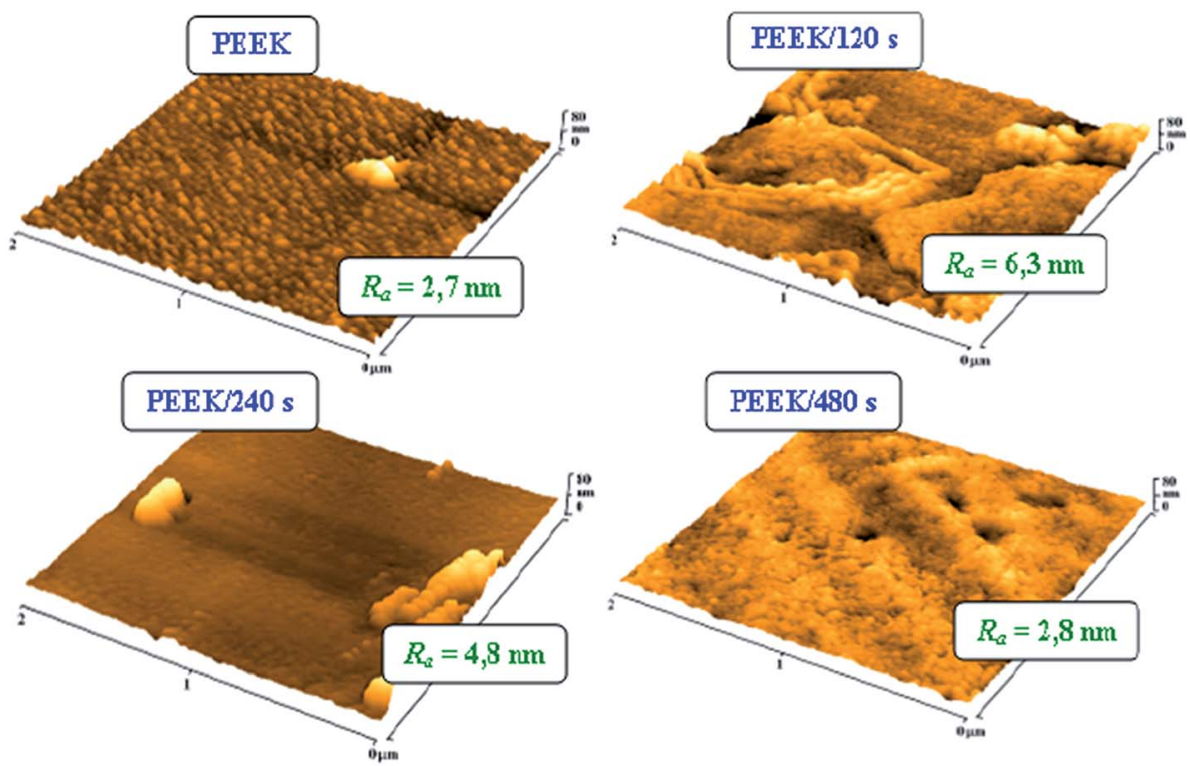

Fig. 1 AFM images of pristine polyetheretherketone [PEEK] and PEEK treated by Ar plasma for 120, 240 and 480 s [PEEK/120 s; PEEK/240 s; PEEK/ $480 \mathrm{~s}] . R_{\mathrm{a}}$ is average surface roughness in $\mathrm{nm}$.

general. The oxygen content increased in the plasma treated samples from $11 \%$ (pristine PEEK) to $48.1 \%$ (PEEK/480 s). This results correlate with goniometric measurements (see Table 1, WCA); degradation prevails during short plasma exposure while ablation occurs after prolonged treatment period. The rise of oxygen concentration is generated by newly created polar oxygen groups, such as, carbonyl, carboxyl and hydroxyl. ${ }^{31}$

The morphological changes of the PEEK surface induced by the Ar plasma treatment were assessed by AFM method. Fig. 1 illustrates a dramatic change in morphology of the PEEK surface before and after plasma treatment for varying treatment times $(0-480 \mathrm{~s})$. Average surface roughness values $\left(R_{\mathrm{a}}\right)$ are included. Globular structures occur on the surface of the

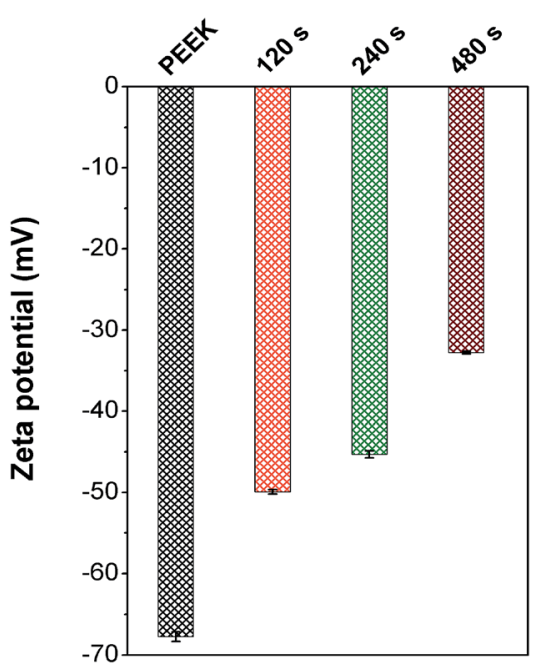

Fig. 2 Zeta potential of pristine polyetheretherketone [PEEK] and PEEK treated by Ar plasma for 120, 240 and 480 s [120, 240 and 480 s]. untreated polymer. Plasma treatment longer than $120 \mathrm{~s}$ led to interconnection of these structures and significant increase of the sample's surface roughness (from 2.7 to $6.3 \mathrm{~nm}$ ). Longer treatment times caused a gradual decrease of the surface roughness (down to $2.8 \mathrm{~nm}$ ) of the polymer, approaching values of pristine PEEK. This was probably caused by a surface preferential ablation of the amorphous polymer phase and a corresponding increase of the crystalline phase. ${ }^{30}$

Results of electrokinetic analysis are presented in Fig. 2 and provide information about surface chemistry and surface charge of samples. Both of these are important factors for a primary cell adhesion and proliferation..$^{32,33}$ From Fig. 2 it is clear, that the value for pristine PEEK $(-68 \mathrm{mV})$ corresponds to

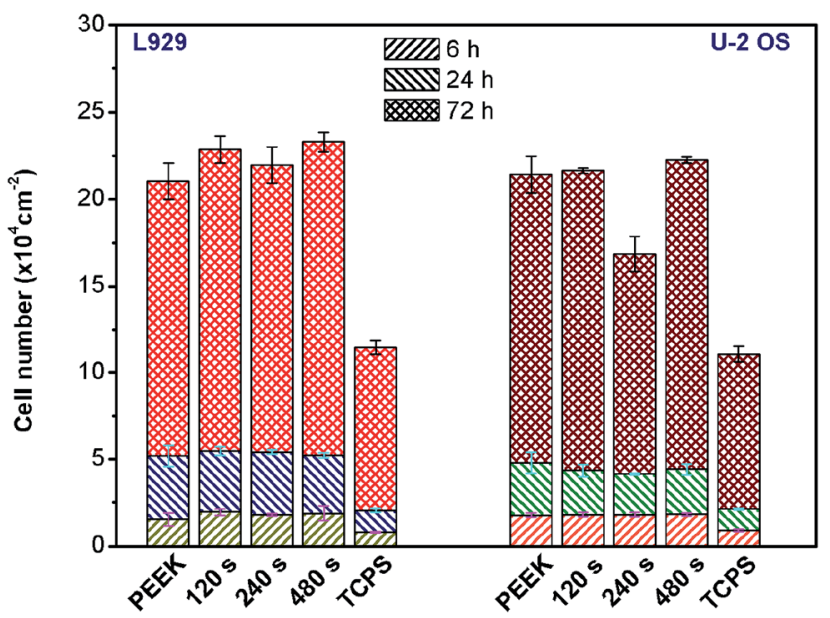

Fig. 3 Dependence of the number of L929 (left side) and U-2 OS (right side) cells cultivated for 6, 24 and $72 \mathrm{~h}$ on pristine polyetheretherketone [PEEK] and treated PEEK scaffolds in the different plasma treating times $[120,240$, and 480 s] and tissue culture polystyrene [TCPS]. 
the strongly hydrophobic surface. ${ }^{34,35}$ The zeta potential is known to depend on the surface chemistry, polarity, charge and the surface morphology and roughness. ${ }^{32,34,35}$ Zeta potential of plasma treated samples dramatically changed to the less negative values due to increasing polarity of samples (see Fig. 2). These results were confirmed also by goniometry and by XPS measurement (see Table 1). Especially presence of oxygen groups on surface (Table 1) corresponds to zeta potential changes well. The higher presence of oxygen groups shows in the less negative zeta potential. ${ }^{34,35}$ The least value of zeta potential was obtained for $480 \mathrm{~s}$ plasma treated PEEK and it corresponds to the highest amount of oxygen group (48.6 at\%, see Table 1).

The aim of activating the PEEK surface by plasma was to increase the surface attractiveness for subsequent cell adhesion and proliferation. L929 and U-2 OS have been chosen as model cell lines, first according to the international standard EN ISO for cytotoxicity and cytocompatibility testing, and secondly for their heterogeneity. The PEEK cytocompatibility was determined based on the results of cell adhesion ( $6 \mathrm{~h})$ and proliferation (24 and 72 h), see Fig. 3, and metabolic activity (WST-1 assay), summarized in Fig. 5. Cell adhesion was monitored $6 \mathrm{~h}$ after seeding the substrate surface with L929 and U-2 OS, by means of fluorescence microscopy. For all PEEK samples, it is

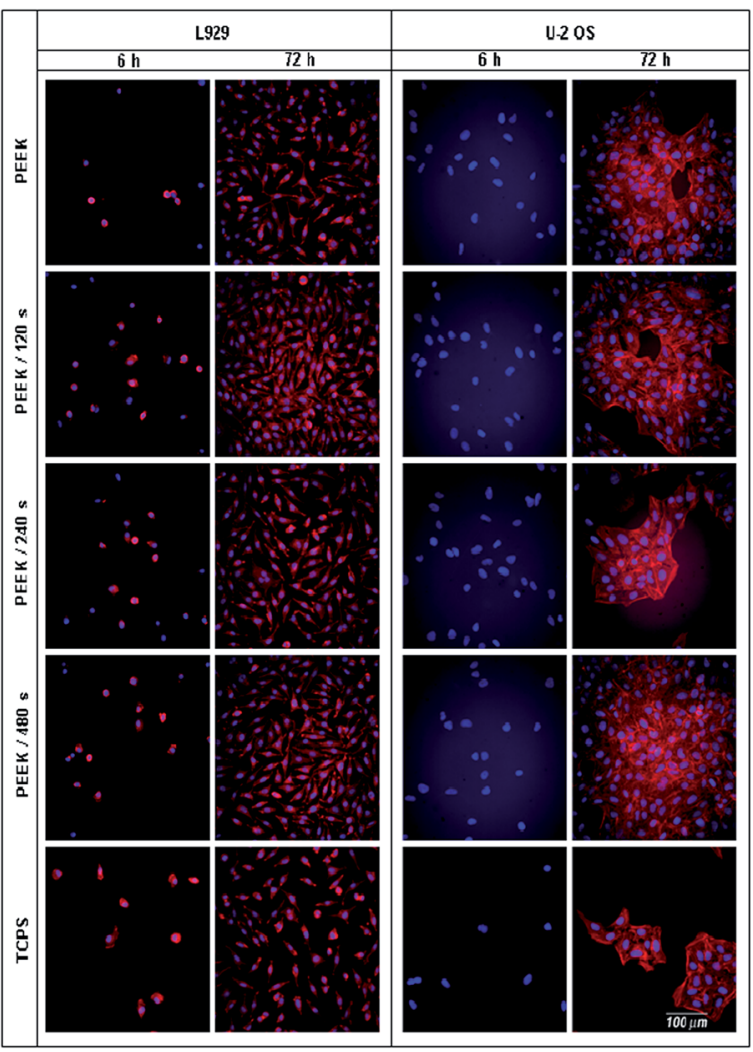

Fig. 4 Fluorescence microscopy images of L929 and U-2 OS cells adhered ( $6 \mathrm{~h}$ ) and proliferated (72 h) on treated polyetheretherketone [PEEK] scaffolds in the following order: pristine polymer [PEEK], plasma treated [120, 240 and $480 \mathrm{~s}$ ] and tissue culture polystyrene [TCPS]. Cell cytoskeleton labeled with phalloidin-Atto 565 and cell nuclei with DAPI. The scale bar of all images corresponds to $100 \mu \mathrm{m}$. apparent that the cell number (L929 and U-2 OS) per one square centimeter was doubled compared to the control tissue culture polystyrene (TCPS). Comparing the number of the cells adhered to pristine and plasma-treated PEEK, we evaluate that the plasma treatment does enhance cell adhesion, however, only moderately. After $24 \mathrm{~h}$ of growth we observed a larger increase in cell number of L929 compared to U-2 OS. After $72 \mathrm{~h}$ of growth, moderate proliferation of L929 cells was detected on PEEK/480 s $\left(1.1 \times 10^{4} \mathrm{~cm}^{-2}\right)$, there was twice as many cells as on control samples of TCPS $\left(9.4 \times 10^{4} \mathrm{~cm}^{-2}\right)$. We observed a moderate increase in cells grown on plasma treated samples than on pristine PEEK. In the case of U-2 OS cells, we observed the most pronounced cell proliferation on PEEK/480 s $\left(17.4 \times 10^{4} \mathrm{~cm}^{-2}\right)$, and the least cells was found on PEEK/240 s $\left(12.7 \times 10^{4} \mathrm{~cm}^{-2}\right)$. A small number of cells can be explained not only by the lowest value of the contact angle $\left(48.3^{\circ}\right)$, and thus too high hydrophilicity of the sample, but also by a change in its surface roughness. The number of cells on a control TCPS was $8.9 \times 10^{4}$ $\mathrm{cm}^{-2}$. Based on these results, we summarize that pristine PEEK is a cytocompatible material with good surface properties significantly better than TCPS and that Ar plasma treatment of a material surface increases its cytocompatibility. From Fig. 3, it is apparent that plasma treatment slightly influenced attachment and proliferation of L929 cells in comparison to pristine PEEK.

Fluorescence microscopy images of L929 and U-2 OS after $6 \mathrm{~h}$ (adhesion) and $72 \mathrm{~h}$ (proliferation) of cultivation on pristine PEEK, plasma treated PEEK and TCPS are shown in Fig. 4. The cultivation of cells for $6 \mathrm{~h}$ was chosen as a sufficiently long time in order to allow the cells to adhere tightly and spread. Both L929 and U-2 OS cells were fixed and stained, the nucleus with DAPI and F-actin with phalloidin-Atto 565, to evaluate these structures by fluorescence microscopy. In Fig. 4, there is shown a comparison of cell morphology and distribution on the tested samples. L929 cells exhibited a round shape pattern on individual PEEK samples and on control TCPS after $6 \mathrm{~h}$ of

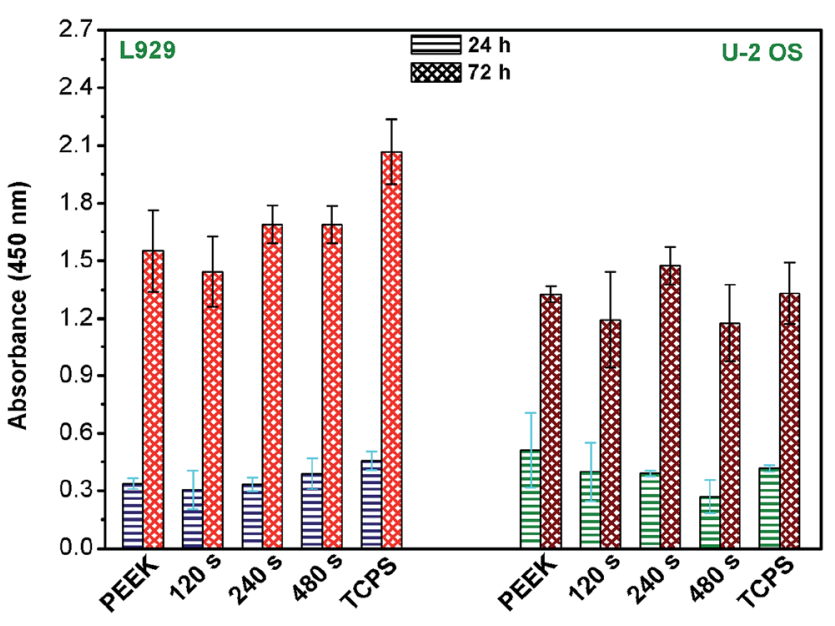

Fig. 5 Dependence of metabolic activity of cells of L929 (left side) and $\mathrm{U}-2$ OS (right side) cultivated for 24 and $72 \mathrm{~h}$ on: pristine polymer [PEEK], plasma treated [120, 240 and 480 s] and tissue culture polystyrene [TCPS]. 
cultivation. After $24 \mathrm{~h}$, the cells were partially spread and already had their typical triangular cell body with 3-4 appendages. After 72 h, L929 cells had the same morphology, they were spread over the entire surface of the samples and their number was increasing. In contrast, U-2 OS cells had their characteristic flat oval shape already $6 \mathrm{~h}$ after seeding. U-2 OS cells are very flat compared to L929 cells. PEEK is a strongly fluorescent material in wavelength range of $350-550 \mathrm{~nm}$, which interferes with fluorescence emission of (400-520 nm, measured in DMSO). Therefore, high fluorescence background is visible in the images of U-2 OS nuclei ( $6 \mathrm{~h}$ after seeding). For this reason, many research groups have not tested PEEK cytocompatibility, because its inherent autofluorescence limits its usability in fluorescence microscopy based analyses. In addition to cell nuclei detection, we evaluated the overall cell morphology by bright field microscopy.

When considering a substrate as a biocompatible material, another factor needs to be taken into account - cell viability. Therefore, we assessed WST-1 test to evaluate viability of L929 and U-2 OS cells growing on individual PEEK substrates and control TCPS, details in Fig. 5. Surprisingly, L929 cells growing on the control TCPS samples for 24 and $72 \mathrm{~h}$ converted more formazan reaching higher absorbance values, which corresponded to enhanced viability contrary to cells proliferating on other PEEK samples. The viability of L929 cells on PEEK/240 s and PEEK/480 s was substantially lower than on control TCPS but it was still enhanced in comparison to pristine PEEK although it was not statistically significant. We observed a decreased cell viability of L929 growing on PEEK/120 s, which might be caused by high average roughness of the polymer surface $\left(R_{\mathrm{a}}=6.3 \mathrm{~nm}\right)$. From Fig. 5 , it is apparent that the viability of the U-2 OS cells growing on pristine PEEK was similar to control. U-2 OS cells showed higher viability on the sample PEEK/240 s, probably for its hydrophilic character $\left(48.3^{\circ}\right)$ and roughness surface $(4.8 \mathrm{~nm})$. Both nano- and microroughness is favorable to the metabolic activity of osteoblasts. ${ }^{36,37}$ The difference in response to the same surfaces of the polymer was caused by selection of various cell lines L929 and U-2 OS.

Next, to evaluate cell surface morphology and intercellular connections in greater detail, we performed high resolution scanning electron microscopy (SEM) analysis (Fig. 6) using preferably L929 cell line because of their more plastic (3D) shape compared to U-2 OS which appeared flat even using such a high resolution technique. L929 cells adhered on the tested substrates exhibited numerous long and thin filopodia, which were the most abundant in cells on plasma treated PEEK, the most then on $480 \mathrm{~s}$ and $120 \mathrm{~s}$ treated samples, respectively. Cells adhered on substrates with low pattern density (plasma treated PEEK) were better adapted to the material topography (based on cells protrusions), then on pristine PEEK with higher nanopatterned density. Remarkably, cells on plasma treated PEEK exhibited in all cases extensions of cell plasma membrane, not though on pristine PEEK and glass microscopic slides used as controls. We suppose that cells adhered on rougher substrates come into a contact with adequate number of attachment sites, which stabilizes the actin filaments and focal contacts associations. This is in agreement with results in (ref. 38).

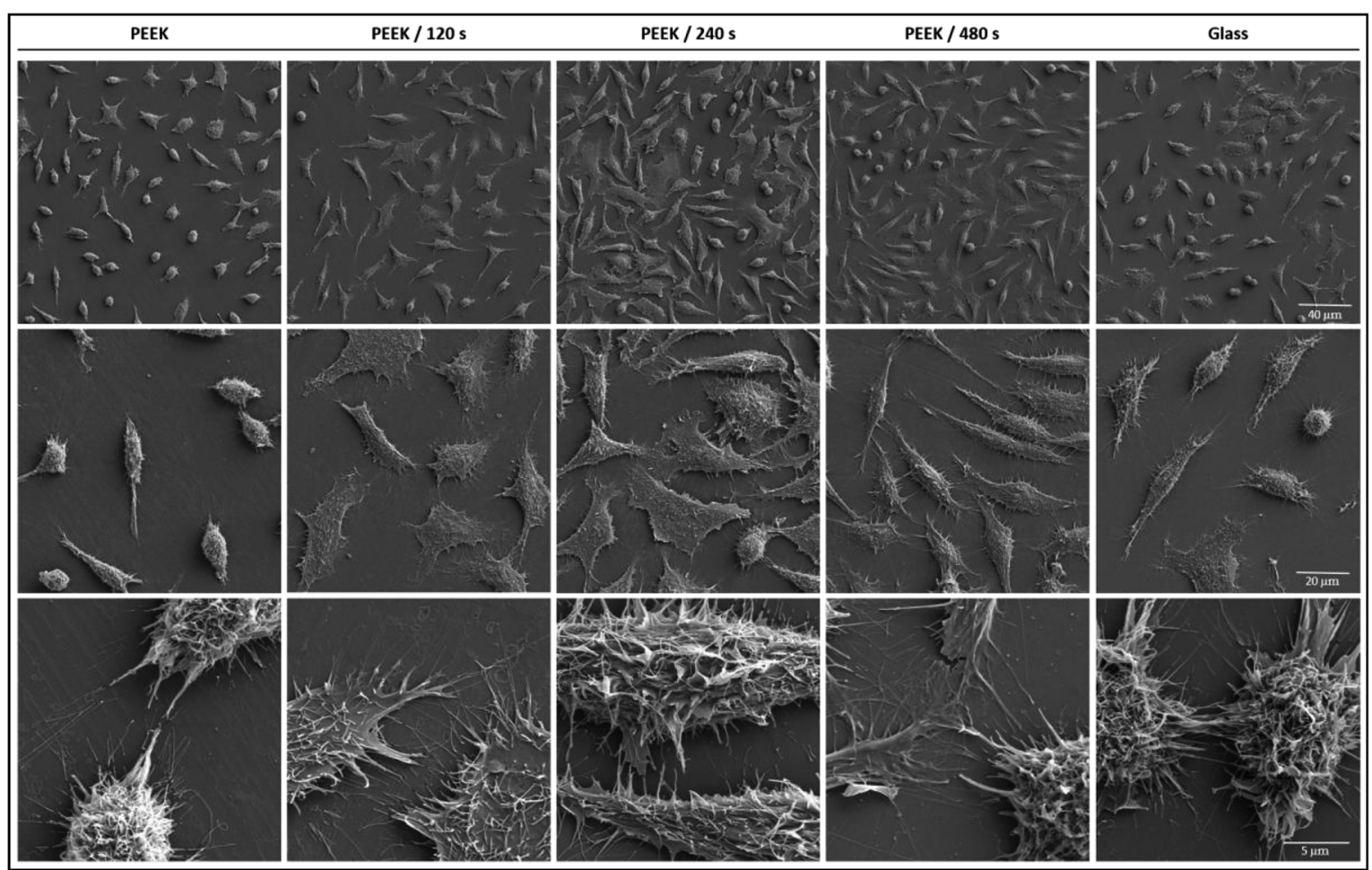

Fig. 6 Scanning electron microscopy (SEM) images of L929 cells cultivated (72 h) on PEEK, plasma treated (120, 240 and 480 s) PEEK matrices and glass microscopic slides. SEM images of three different magnifications. 

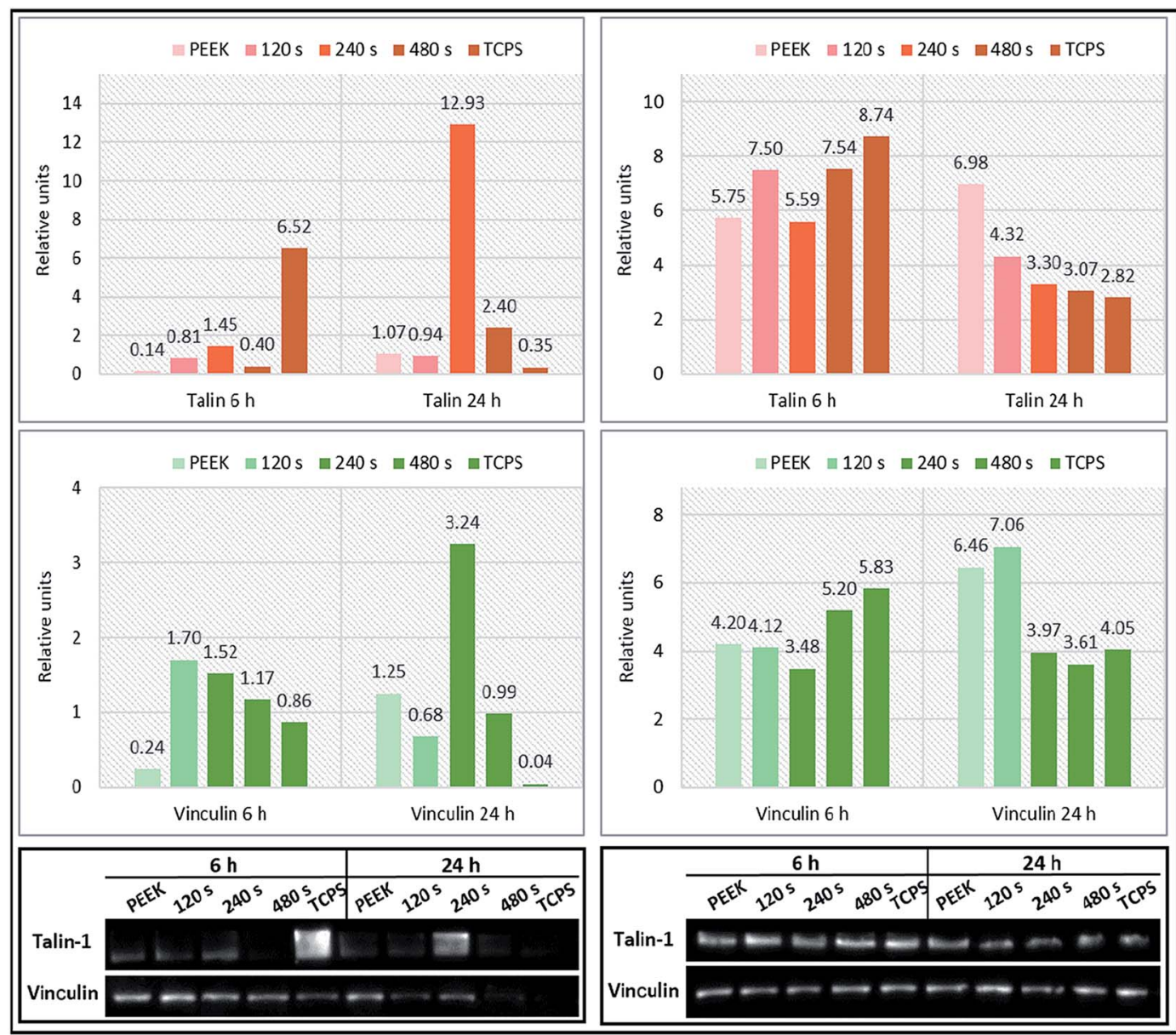

Fig. 7 Expression profiles of adhesion proteins talin 1 and vinculin in L929 (left panel) and U-2 OS (right panel) cells based on the cultivation substrate (pristine and plasma treated PEEK and TCPS). The cells were adhered and grown for 6 and 24 h, respectively. Total cell lysates were used for talin 1 and vinculin detection. Normalization was done using GAPDH.

Interestingly, U-2 OS monitored by SEM has shown smooth surface with visible nucleus and nucleoli, no observable differences were noted among the individual substrates (data not shown).

The initial interactions of cells with a biomaterial involve their attachment, actin cytoskeleton reorganization and spreading. Anchorage-dependent cells growing on a substratum rely on stable adhesion on a surface, this event is absolutely crucial for their survival. Cell attachment is not direct, but it is mediated through a protein layer and it is achieved by contact points - focal adhesions - which are randomly distributed. ${ }^{39} \mathrm{We}$ investigated the effect of substrate surface characteristics on the level of cell adhesion based on the production of two adhesion markers, talin 1 and vinculin proteins detected in L929 and U-2 OS lysates of cells growing on PEEK substrates for 6 and $24 \mathrm{~h}$. Vinculin is a protein present in focal adhesion plaques, which is involved in linkage to actin via integrin adhesion molecules. ${ }^{39}$ The expression level of endogenous adhesion proteins was measured by Western blot, quantified and normalized on glyceraldehyde-3-phosphate dehydrogenase (GAPDH; a constitutively expressed protein). The results are summarized in Fig. 7. Surprisingly, $6 \mathrm{~h}$ after seeding, talin 1 expression was significantly reduced in L929 cells growing on pristine PEEK and plasma treated PEEK when compared to TCPS. Because talin 1 is the major force driving cell adhesion and spreading kinetics, decrease in its production results in reduced cell spreading. ${ }^{40}$ Interestingly, after $24 \mathrm{~h}$, the highest level of talin 1 expression was found for $\mathrm{L} 929$ cells growing on PEEK treated by plasma for $240 \mathrm{~s}$. Regarding U-2 OS cells, $6 \mathrm{~h}$ after seeding, the level of talin 1 in cells on individual PEEK surfaces and TCPS did not differ so much as in the case of L929 cells. After $24 \mathrm{~h}$, there was a descending character in talin 1 amount in the following order: PEEK, PEEK 120 s, PEEK 240 s, PEEK 480 s and TCPS. Another of the key players of cellular adhesion, is vinculin. More specifically, its synthesis influences cell shape, motility, and adhesion-dependent growth ability. ${ }^{41}$ Vinculin expression was in L929 cells adhered on plasma treated PEEK was pronounced when compared to pristine PEEK $6 \mathrm{~h}$ after seeding. In correlation with talin 1 level after $24 \mathrm{~h}$, the highest amount of vinculin after $24 \mathrm{~h}$ was found in cells growing on PEEK treated for $240 \mathrm{~s}$. The results differed for both cell lines which might be given by the fact that they are of different origin and express different cell surface receptors, such as integrins responsible for cell attachment. ${ }^{42}$ 


\section{Conclusions}

We treated PEEK surface using Ar plasma and improved its chemical and physical properties in order to provide a suitable and cytocompatible support for cell culture. The plasma treatment led to substantial changes in the surface chemistry, polarity (wettability) of PEEK samples, furthermore polymer surface morphology and roughness were significantly altered, too. The treated PEEK surface was more hydrophilic, more rugged and rougher than pristine PEEK. These effects were dependent on the plasma treatment exposure time. It was confirmed by XPS measurement, goniometry, electrokinetic analysis and atomic microscopy. Further, we have assessed in vitro tests to evaluate cytocompatibility of the plasma treated PEEK. We found that the treatment resulted in enhanced cell adhesion and proliferation of two model cell lines (L929 and U-2 OS), when compared to pristine PEEK. Scanning electron microscopy analysis supported our observations by revealing pronounced number of filopodia in L929 cells growing on plasma treated PEEK (especially by 480 and $120 \mathrm{~s}$ treatment). Interestingly, talin 1 and vinculin, which expression was determined as a measure of cell adhesion, was pronounced mostly on PEEK treated by plasma for $240 \mathrm{~s}$ (for $24 \mathrm{~h}$ ).

In summary, we show that plasma treatment is an attractive approach for increasing cytocompatibility of PEEK polymer and that it significantly improves its properties compared to pristine PEEK.

\section{Acknowledgements}

This work was supported by the GACR under projects 14-18149P (A.R.), 108/12/G108 and by financial support from specific university research MSMT no. 20/2015 (Z.N.).

\section{Notes and references}

1 S. M. Kurtz and J. N. Devine, Biomaterials, 2007, 28, 48454869.

2 F. Awaja, D. Bax, S. Zhang, N. James and D. R. McKenzie, Plasma Processes Polym., 2012, 9, 355-362.

3 R. Ma, S. Tang, H. Tan, J. Qian, W. Lin, Y. Wang, C. Liu, J. Wei and T. Tang, ACS Appl. Mater. Interfaces, 2014, 6, 12214-12225.

4 M. L. Hwang, J. M. Song, B. S. Ko, J. Y. Sohn, Y. C. Nho and J. Shin, Nucl. Instrum. Methods Phys. Res., Sect. B, 2012, 281, 45-50.

5 T. Kobayashi, M. Rikukawa, K. Sanui and N. Ogata, Solid State Ionics, 1998, 106, 219-225.

6 A. Katzer, H. Marquardt, J. Westendorf, J. V. Wening and G. Foerster, Biomaterials, 2002, 23, 1749-1759.

7 C. H. Rivard, S. Rhalmi and C. Coillard, J. Biomed. Mater. Res., 2002, 62, 488-498.

8 T. Nieminen, I. Kallela, E. Wuolijoki, H. Kainulainen, I. Hiidenheimo and I. Rantala, J. Biomed. Mater. Res., Part A, 2008, 84, 377-383.
9 K. B. Sagomonyants, M. L. Jarman-Smith, J. N. Devine, M. S. Aronow and G. A. Gronowicz, Biomaterials, 2008, 29, 1563-1572.

10 E. Kitamura, R. Stegaroiu, S. Nomura and O. Miyakawa, Clin. Oral. Implants Res., 2004, 15, 401-412.

11 J. Althaus, C. Padeste, J. Köser, U. Pieles, K. Peters and B. Müller, Eur. J. Nanomed., 2012, 4, 7-15.

12 Y. Wang and E. J. Terrell, Wear, 2013, 303, 255-261.

13 O. Noiset, Y. J. Schneider and J. Marchand-Brynaert, J. Biomater. Sci., Polym. Ed., 1999, 10, 657-677.

14 L. Ponsonnet, K. Reybier, N. Jaffrezic, V. Comte, C. Lagneau, M. Lissac and C. Martelet, Mater. Sci. Eng., C, 2003, 23, 551-560. 15 Y. P. Jiao and F. Z. Cui, Biomed. Mater., 2007, 2, R24-R37.

16 H. K. Tsou, P. Y. Hsieh, C. J. Chung, C. H. Tang, T. W. Shyr and J. L. He, Surf. Coat. Technol., 2009, 204, 1121-1125.

17 D. Briem, S. Strametz, K. Schrooder, N. M. Meenen, W. Lehmann, W. Linhart, A. Ohl and J. M. Rueger, J. Mater. Sci.: Mater. Med., 2005, 16, 671-677.

18 Y. Choi, J. Kim, K. Paek, W. Ju and Y. S. Hwang, Surf. Coat. Technol., 2005, 193, 319-324.

19 M. Kuzuya, S. Kondo, M. Sugito and T. Yamashiro, Macromolecules, 1998, 31, 3230-3234.

20 V. Svorcik, K. Kolarova, P. Slepicka, A. Mackova, M. Novotna and V. Hnatowicz, Polym. Degrad. Stab., 2006, 91, 1219-1225.

21 C. M. Chan, T. M. Ko and H. Hiraoka, Surf. Sci. Rep., 1996, 24, 3-54.

22 A. Reznickova, Z. Novotna, Z. Kolska and V. Svorcik, Nanoscale Res. Lett., 2014, 9(305), 1-6.

23 V. Svorcik, Z. Kolska, T. Luxbacher and J. Mistrik, Mater. Lett., 2010, 64, 1160-1162.

24 S. Rimpelova, N. Slepickova Kasalkova, P. Slepicka, H. Lemerova, V. Svorcik and T. Ruml, Mater. Sci. Eng., C, 2013, 33, 1116-1124.

25 S. Rimpelova, L. Peterkova, N. Slepickova Kasalkova, P. Slepicka, V. Svorcik and T. Ruml, Plasma Processes Polym., 2014, 11, 1057-1067.

26 S. Husain and U. Luthra, Curr. Sci., 1993, 64, 681-682.

27 I. S. Watanabe, K. Ogawa, D. P. Cury, F. J. Dias, M. C. K. Sosthenes, J. P. M. Issa and M. M. Iyomasa, Microsc. Res. Tech., 2013, 76, 1226-1233.

28 V. Svorcik, V. Kotal, O. Blahova, M. Spirkova, P. Sajdl and V. Hnatowicz, Nucl. Instrum. Methods Phys. Res., Sect. B, 2006, 244, 365-372.

29 V. Svorcik, V. Kotal, P. Slepicka, O. Blahova, M. Spirkova, P. Sajdl and V. Hnatowicz, Nucl. Instrum. Methods Phys. Res., Sect. B, 2006, 224, 365-372.

30 P. Slepicka, N. Slepickova Kasalkova, E. Stranska, L. Bacakova and V. Svorcik, eXPRESS Polym. Lett., 2013, 7, 535-545.

31 A. Reznickova, Z. Kolska, V. Hnatowicz, P. Stopka and V. Svorcik, Nucl. Instrum. Methods Phys. Res., Sect. B, 2011, 269, 83-88.

32 Z. Kolska, A. Reznickova, M. Nagyova, N. Slepickova Kasalkova, P. Sajdl, P. Slepicka and V. Svorcik, Polym. Degrad. Stab., 2014, 101, 1-9.

33 L. Bacakova, E. Filova, M. Parizek, T. Ruml and V. Svorcik, Biotechnol. Adv., 2011, 29, 739-767. 
34 Z. Kolska, A. Reznickova and V. Svorcik, e-Polymer, 2012, 083, $1-13$.

35 B. J. Kirby and E. F. Hasselbrink Jr., Electrophoresis, 2004, 25, 187-202.

36 S. Lossdorfer, Z. Schwartz, L. Wang, C. H. Lohmann, J. D. Turner, M. Wieland, D. L. Cochran and B. D. Boyan, J. Biomed. Mater. Res., Part A, 2004, 361-369.

37 R. Olivares-Navarrete, S. L. Hyzy, R. A. Gittens, J. M. Schneider, D. A. Haithcock, P. F. Ullrich, P. J. Slosar, Z. Schwartz and B. D. Boyan, J. Spine, 2013, 13, 1563-1570.
38 J. V. Small, K. Rottner, I. Kaverina and K. I. Anderson, Biochim. Biophys. Acta, Mol. Cell Res., 1998, 1404, 271-281.

39 B. Hiebl, K. Lützow, M. Lange, F. Jung, B. Seifert, F. Klein, T. Weigel, K. Kratz and A. Lendlein, J. Biotechnol., 2010, 148, 76-82.

40 J. W. Lee, K. B. Lee, H. S. Jeon and H. K. Park, Anal. Sci., 2011, 27, 369-374.

41 C. Albigés-Rizo, P. Frachet and M. R. Block, J. Cell Sci., 1995, 108, 3317-3329.

42 F. M. Watt, EMBO J., 2002, 21, 3919-3926. 